ORIGINAL ARTICLE

\title{
Injury prevention training: a cluster randomised controlled trial assessing its effect on the knowledge, attitudes, and practices of midwives and health visitors
}

\author{
A Woods, J Collier, D Kendrick, K Watts, M Dewey, R Illingworth
}

Injury Prevention 2004;10:83-87. doi: 10.1136/ip.2003.003475

See end of article for authors' affiliations

Correspondence to: Amanda Woods, Division of Primary Care, 1401 Tower Building, University Park, Nottingham NG7 2RD, UK; amanda. woods@nottingham.ac.uk

\begin{abstract}
Objective: To evaluate the effectiveness of injury prevention training.
Design: Cluster randomised controlled trial.

Setting: Primary care facilities in the East Midlands area of the United Kingdom.

Subjects: Midwives and health visitors.

Intervention: Evidence based training session on the risks associated with baby walkers.

Main outcome measures: The primary outcome measures were knowledge of baby walker use and walker related injury, attitudes towards walkers and towards walker education, and practices relating to walker health education.

Results: Trained midwives and health visitors had greater knowledge of the risks associated with baby walkers than untrained midwives and health visitors (difference between the means $0.22 ; 95 \%$ confidence interval (CI) 0.12 to 0.33 ). Trained health visitors had more negative attitudes to baby walkers (difference between the means $0.35 ; 95 \% \mathrm{Cl} 0.10$ to 0.59 ) and more positive attitudes towards baby walker health education (difference between the means $0.31 ; 95 \% \mathrm{Cl} 0.00$ to 0.62 ) than untrained health visitors. Midwives who had been trained were more likely to discuss baby walkers in the antenatal period than those who were not trained (odds ratio $9.92 ; 95 \% \mathrm{Cl} 2.02$ to 48.83 ).

Conclusions: Injury prevention training was associated with increased knowledge, more negative attitudes towards walkers, and more positive attitudes towards walker education. Trained midwives were more likely to give advice antenatally. Training did not impact on other practices. Larger trials are required to assess the impact of training on parental safety behaviours, the adoption of safety practices, and injury reduction.
\end{abstract}

W hile training health and other professionals in injury prevention is seen as having an important role in the prevention of unintentional injury, the literature available identifies gaps in practice, barriers to training, and few rigorous evaluations of such training. ${ }^{1-7}$ Some studies have shown that training has positive effects. One study found that paediatric residents undergoing an educational intervention increased the amount of violence prevention guidance provided to their patients and families. ${ }^{4}$ In the United Kingdom, a non-randomised study concluded that injury prevention education and training was effective in increasing knowledge and some practices of health professionals. ${ }^{3}$ A randomised trial found parents seen by physicians who had been trained received significantly more injury prevention counselling and were more satisfied than those who had not been trained. ${ }^{6}$ In the United Kingdom, the Department of Health has targeted injury prevention as a priority. ${ }^{8}$ In primary care, nurses have a key part to play in promoting child health, and training health professionals in injury prevention has been recommended. ${ }^{9}$ The care of mothers and babies is via multidisciplinary primary health care teams which include midwives, health visitors, and general practitioners usually based in the locality where the family live. The midwife sees the mother antenatally and around birth and then transfers the care of the child and family to the health visitor until the child reaches the age of 5 . Contacts are carried out at dedicated child health clinics and at home. We report on a study conducted as part of a larger randomised controlled trial of an educational package delivered by midwives and health visitors aimed at reducing baby walker use. As part of this trial we provided training to the intervention group midwives and health visitors. The objectives of the training were to increase knowledge about walkers and walker related injuries, change attitudes towards walkers, and to increase walker health education practice. This paper presents the results of the trial evaluating the effect of the training on knowledge, attitudes, and health education practice of midwives and health visitors.

\section{METHODS \\ Participants}

Between spring and autumn 2000, 86 general practices in the East Midlands area of the United Kingdom were approached to take part in the randomised controlled trial of an educational package delivered by midwives and health visitors aimed at reducing baby walker use. The local research ethics committee gave ethical clearance for the study and the relevant midwife and health visitor managers gave their consent for the midwives and health visitors to be approached. Sixty four practices agreed to take part $(74 \%)$ in the main trial, comprising 46 clusters. Midwives $(n=69)$ and health visitors $(n=64)$ from 42 of these clusters took part in the evaluation of the training. The remaining four clusters were enrolled in the study after the training evaluation. The areas in which they worked included inner city, suburban, and rural areas with Townsend scores (a census based measure of deprivation), ${ }^{10}$ ranging from -3.31 (affluent) to 4.97 (deprived). 


\section{Intervention}

The intervention group midwives and health visitors all attended a 90 minute training session. This included (i) a quiz exploring baby walker use and the epidemiology of baby walker related injuries, (ii) a role play of delivering the intervention using the materials to be used in the trial, and (iii) feedback on the quiz and role play. For midwives it also included training in obtaining informed consent and in recruiting women to the study. The training was standardised and was carried out by researchers working on the trial (RI, AW, DK, KW, JC) The control group midwives and health visitors were aware that the study was about injury prevention but not specifically about baby walkers. Control group midwives were trained in obtaining informed consent and in recruiting women to the study.

\section{Objective}

To evaluate the effectiveness of training on the knowledge, attitudes, and practices of participating midwives and health visitors

\section{Outcomes}

The primary outcome measures were knowledge of baby walker use and walker related injury, attitudes towards walkers and towards walker education, and practices relating to walker health education.

Outcomes were measured by self completion questionnaire at baseline and follow up. Knowledge questions were developed from a review of the Home Accident Surveillance System database ${ }^{11}$ and the literature, and attitude and practice questions from focus groups conducted with health professionals and parents and other literature. ${ }^{12}$ The resultant structured questionnaire was divided into four sections, asking mainly closed questions with a choice of response. Section A (box 1) examined midwives' and health visitors' current practice regarding baby walker health education, including how often they were asked about walkers, if they had any materials for discussing walkers, what influences their discussions with parents and for health visitors what alternatives they suggested when discussing baby walkers (for example, play pen, floor play). Section B examined whether those who had their own children had used baby walkers and had any accidents. Section C (box 2) examined the midwives' and health visitors' attitudes towards baby walkers and their views about delivering baby walker health education. In this section respondents were asked to rate their agreement with a series of statements about baby walkers using a five point Likert scale ranging from "strongly agree" to "strongly disagree". Section D (box 3) contained six knowledge based questions including prevalence of walker use, walker related injury rates, the age at which most walker related injuries occur, the most common mechanisms of injury, and the part of the body most likely to be injured.

The questionnaire was piloted on 22 midwives and health visitors in a neighbouring community trust not taking part in the study, and amended with minor word changes. The baseline questionnaire was sent with a covering letter and reply paid envelope to all 69 midwives and 64 health visitors before the trial commenced. Non-responding midwives and health visitors in the intervention arm were handed the questionnaire to complete at the start of their training session. Non-responding midwives and health visitors in the control arm were followed up by a postal reminder then by a telephone reminder. Follow up questionnaires were sent to all participating midwives and health visitors six months after training.
Box 1: Questions asked of the midwife and health visitor about their practice in relation to baby walkers and used in the creation of scores

- Walkers are discussed at antenatal checks between 28 weeks and delivery (asked of midwives only).

- Walkers are discussed in the puerperium lasked of midwives only).

- I discuss walkers at the birth visit lasked of health visitors only).

- I discuss walkers at the 3-4 month hip check (asked of health visitors only).

- I discuss walkers at the 6-9 month review lasked of health visitors only).

\section{Sample size}

Forty six clusters were required to achieve the desired sample size for the primary outcome for the main trial assessing the effect of an educational package in reducing baby walker use. The analyses presented here are based on 42 clusters of health visitors and midwives who participated in the evaluation of the training.

\section{Randomisation}

The practices to which the midwives and health visitors were attached were stratified by Townsend score ${ }^{10}$ into three strata

Box 2: Questions asked about midwife and health visitor attitudes towards baby walkers and baby walker health education and used in the creation of scores

\section{Attitudes to baby walkers}

- Babies can be safe in walkers if supervised.

- Walkers can delay walking.

- I think we should ban walkers.

- The more time a baby spends in a walker, the more likely they are to have an accident.

- Babies are less likely to have an accident in a walker than a push chair.

- I think baby walkers are useful.

- Modern baby walkers are safe (asked of health visitors only).

- Not many parents experience accidents with walkers (asked of health visitors only).

Attitudes to baby walker health education

- Giving advice about baby walkers before birth is too early (asked of midwives only).

- It is not the midwife's role to advise on baby walkers (asked of midwives only).

- People should be encouraged to decline walkers as presents (asked of midwives only).

- Parents should be advised not to get a walker lasked of midwives only).

- Parents should be advised to use a walker for a limited amount of time per day (asked of health visitors only).

- It's hard to persuade people not to use walkers as they think they are useful (asked of health visitors only).

- I don't think what we say about walkers influences parents much (asked of health visitors only).

- Parents expect us to inform them about baby walkers (asked of health visitors only). 
Box 3: Knowledge questions asked of midwives and health visitors and used in the creation of scores (correct response in italics)

- Percentage of infants that use a walker (50\%).

- Proportion of infants using a walker who have walker related injury (between 1 in 8 and 1 in 2).

- Proportion of infants who continue to be placed in a walker after walker related injury (2/3).

- Age at which most walker related injuries occur (9-12 months).

- Part of body, most commonly injured (head and neck).

- Most common mechanism of walker related injury (fall from or on stairs or steps).

and randomly allocated within strata to the treatment arms. The allocation schedule was computer generated by two of the researchers (DK, AW) and allocation was undertaken by another researcher (RI) blind to the identity of the practices. Where the midwife or health visitor were attached to more than one practice, all the practices that they were attached to were allocated to treatment groups as one cluster. There were 42 clusters of between one and eight practitioners.

\section{Blinding}

It was not possible to blind midwives and health visitors regarding treatment arm assignment. The analyses were not undertaken blind to treatment arm assignment.

\section{Statistical methods}

All questionnaire data were double entered into a Microsoft Access database and any discrepancies identified and corrected by reference to the original questionnaire. The data were checked, cleaned, and exported into SPSS version 11 for analysis. Scales were created from the sections on the questionnaire, covering midwives' and health visitors' attitudes toward baby walkers and midwives' and health visitors' attitudes to baby walker health education. The individual questions concerning attitudes towards walkers were recoded so that negative views of walkers received a high score. The individual questions concerning walker health education were recoded so that a positive view towards walker education received a high score. Scores were summed and divided by the number of questions answered to produce a score for each individual. Item analysis was undertaken. Inter-item, item whole correlations and Cronbach's alpha were calculated. A knowledge score was computed by assigning a value of 1 to correct responses and 0 to incorrect responses. These values were then summed across all six knowledge questions and divided by the number of questions answered by the midwife or health visitor.

Knowledge and attitude scores were compared between the intervention and control group, at follow up using random effects linear regression, (a) unadjusted for baseline score and (b) adjusted for baseline score. The proportion of health professionals giving advice about walkers in the intervention and control groups at follow up were compared using random effects logistic regression, (a) unadjusted for baseline practice and (b) adjusted for baseline practice. Random intercepts models were used with health professional at level 1 and cluster at level 2. These analyses were undertaken using Stata version 8. Analyses were undertaken on an intention to treat basis. Those with missing follow up data were included only in the baseline analysis.

\section{RESULTS}

\section{Recruitment}

A total of 133 community practitioners were recruited between spring and autumn 2000, 126 of whom were randomised (64 midwives and 62 health visitors). Figure 1 shows the flow of participants through each stage of the trial.

Baseline data are shown in table 1 . The response rate to the baseline questionnaire was $95 \%(\mathrm{n}=59)$ for health visitors and $88 \%(\mathrm{n}=56)$ for midwives. Intervention arm midwives and health visitors had a slightly lower knowledge scores, intervention arm midwives had slightly more negative attitudes towards walkers and intervention arm health visitors had slightly more positive attitudes towards walker health education. Intervention group midwives were less likely than control group midwives to discuss walkers antenatally or around birth.

Table 2 shows differences in the mean knowledge and attitude scores between treatment arms, unadjusted and adjusted for baseline scores. It also shows the odds ratio for each practice, unadjusted and adjusted for baseline practice. At follow up, intervention arm midwives and health visitors had a significantly higher knowledge score than those in the control arm. Intervention arm health visitors had significantly more negative attitudes towards walkers and intervention arm midwives were significantly more likely to give advice regarding walkers in the antenatal period than those in the control arm. There was some evidence to suggest that intervention arm health visitors and midwives hold more positive attitudes towards walker health education than those in the control group.

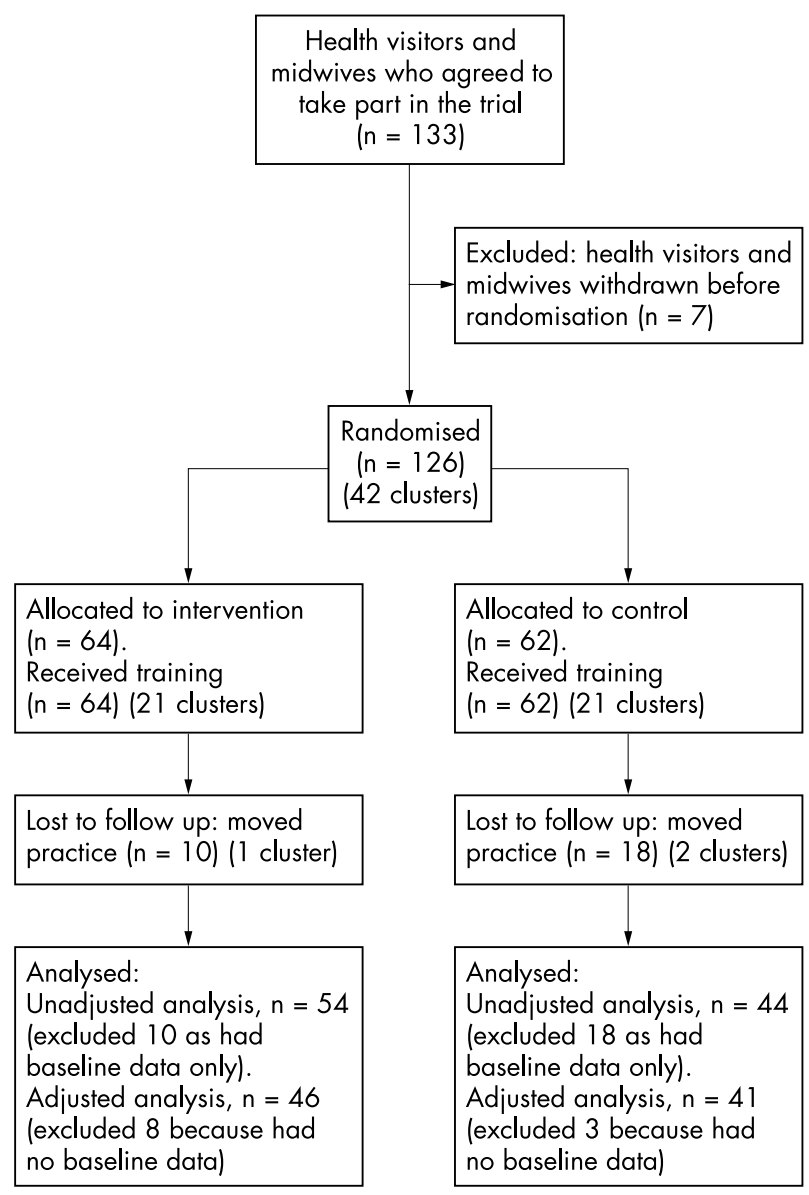

Figure 1 Flow of participants through the trial. 
Table 1 Baseline knowledge, attitudes, and practice of midwives and health visitors [missing values]

\begin{tabular}{|c|c|c|}
\hline & Intervention & Control \\
\hline \multicolumn{3}{|l|}{ Knowledge and attitude scores; values are mean (SD) } \\
\hline $\begin{array}{l}\text { Midwives' and health visitors' knowledge of the } \\
\text { risks associated with baby walkers[1] }\end{array}$ & $0.39(0.29)$ & $0.45(0.27)$ \\
\hline Midwives' attitude towards baby walkers ${ }^{a}$ & $3.30(0.67)$ & $3.12(0.47)$ \\
\hline Midwives' attitude to baby walker health education ${ }^{b}[1]$ & $3.34(0.67)$ & $3.33(0.67)$ \\
\hline Health visitors' attitude towards baby walkers ${ }^{c}$ & $3.80(0.53)$ & $3.79(0.51)$ \\
\hline Health visitors' attitude to baby walker health education ${ }^{\mathrm{d}}[2]$ & $3.09(0.54)$ & $2.87(0.75)$ \\
\hline \multicolumn{3}{|l|}{ Practice scores; values are frequency $(\%)$} \\
\hline Midwife discusses antenatally* & $4(15.4)$ & $6(20)$ \\
\hline Midwife discusses around birth*[1] & $9(36)$ & $14(47)$ \\
\hline Health visitor discusses around birth $+[8]$ & $14(53.8)$ & $14(56)$ \\
\hline Health visitor discusses between 4-6 months $+[7]$ & $10(37)$ & $8(32)$ \\
\hline Health visitor discusses between 6-9 months $+[3]$ & $23(79.3)$ & $21(77.7)$ \\
\hline $\begin{array}{l}\text { Cronbach's alpha } a=0.75, b=0.76, c=0.75, d=0.61 \text {. } \\
\text { *Dichotomised as always, often or sometimes } v \text { never. } \\
\text { †Dichotomised as always or often } v \text { sometimes or never. }\end{array}$ & & \\
\hline
\end{tabular}

\section{DISCUSSION}

\section{Principal findings}

Our main findings were that injury prevention training was associated with greater knowledge regarding walker use and walker related injury among midwives and health visitors, more negative attitudes towards walkers and more positive attitudes to walker health education among health visitors, and an increase in the frequency of advising about walkers in the antenatal period among midwives.

\section{Strengths and weaknesses of the study}

This is one of the few randomised controlled trials evaluating injury prevention training. Although we achieved a high follow up rate in the intervention arm $(84 \%$ for the unadjusted analysis) the follow up rate was lower (71\% for the unadjusted analysis), due almost entirely to changes in staffing, among those in the control arm. We have no reason to believe that those practitioners who moved practices during the course of the study would differ in terms of knowledge, attitudes, or practices from those who did not move practices, so it is unlikely that this would bias our results. However as the sample size was restricted to those taking part in the trial of an educational package in reducing baby walker use, we had a low power to detect some of the outcomes and particularly to detect changes in practice. A post hoc power calculation indicated that we had $80 \%$ power at the 5\% significance level (two sided ) to detect a $17 \%$ point difference for health visitors discussing walkers at the 6-9 month check and 30\% points for the remaining activities. These are large changes in practice, so it is possible that our study may have failed to detect smaller, but clinically important, changes in practice. In addition the percentage of health visitors advising about walkers at baseline and follow up was high, particularly at the 6-9 month check, so making it difficult to detect a difference between the treatment arms. Within this trial we have relied on self reported knowledge, attitudes, and practice. While intervention arm health visitors and midwives may be more likely to

Table 2 Follow up knowledge, attitudes, and practice by treatment group, unadjusted and adjusted for baseline score or practice

\begin{tabular}{|c|c|c|c|c|}
\hline & Intervention & Control & $\begin{array}{l}\text { Difference between means } \\
\text { unadjusted for baseline } \\
\text { score }(95 \% \mathrm{Cl})\end{array}$ & $\begin{array}{l}\text { Difference between means } \\
\text { adjusted for baseline score } \\
(95 \% \mathrm{CI})\end{array}$ \\
\hline \multicolumn{5}{|l|}{ Knowledge and attitude scores; values are mean (SD) } \\
\hline $\begin{array}{l}\text { Midwife and health visitor knowledge of the risks } \\
\text { associated with baby walkers }\end{array}$ & $0.59(0.27)$ & $0.37(0.24)$ & $\begin{array}{l}0.22(0.12 \text { to } 0.33) \\
p<0.0001\end{array}$ & $\begin{array}{l}0.22(0.12 \text { to } 0.33) \\
p<0.0001\end{array}$ \\
\hline Midwife attitude towards baby walkers & $3.69(0.46)$ & $3.41(0.60)$ & $\begin{array}{l}0.26(-0.55 \text { to } 0.58) \\
p=0.105\end{array}$ & $\begin{array}{l}0.18(-0.16 \text { to } 0.51) \\
p=0.31\end{array}$ \\
\hline $\begin{array}{l}\text { Midwife attitude to baby walker health } \\
\text { education }\end{array}$ & $3.87(0.33)$ & $3.45(0.74)$ & $\begin{array}{l}0.43(0.07 \text { to } 0.78) \\
p=0.018\end{array}$ & $\begin{array}{l}0.35(-0.02 \text { to } 0.72) \\
p=0.06\end{array}$ \\
\hline Health visitor attitude towards baby walkers & $3.89(0.49)$ & $3.59(0.46)$ & $\begin{array}{l}0.30(0.01 \text { to } 0.58) \\
p=0.04\end{array}$ & $\begin{array}{l}0.35(0.10 \text { to } 0.59) \\
P=0.005\end{array}$ \\
\hline $\begin{array}{l}\text { Health visitor attitude to baby walker health } \\
\text { education }\end{array}$ & $3.36(0.52)$ & $2.98(0.58)$ & $\begin{array}{l}0.46(0.14 \text { to } 0.78) \\
p=0.005\end{array}$ & $\begin{array}{l}0.31(0.00 \text { to } 0.62) \\
p=0.047\end{array}$ \\
\hline Practice scores; values are frequency (\%) & & & $\begin{array}{l}\text { Odds ratio unadjusted for } \\
\text { baseline }(95 \% \mathrm{Cl})\end{array}$ & $\begin{array}{l}\text { Odds ratio adjusted for baseline } \\
(95 \% \mathrm{Cl})\end{array}$ \\
\hline Midwife discusses antenatally* & $20(90.9)$ & $10(41.7)$ & $\begin{array}{l}9.0(1.96 \text { to } 41.7) \\
p=0.005\end{array}$ & $\begin{array}{l}9.92(2.02 \text { to } 48.83) \\
p=0.005\end{array}$ \\
\hline Midwife discusses around birth* & $15(68.2)$ & $14(56)$ & $\begin{array}{l}1.76(0.63 \text { to } 4.87) \\
p=0.28\end{array}$ & $\begin{array}{l}1.51(0.49 \text { to } 4.62) \\
p=0.47\end{array}$ \\
\hline Health visitor discusses around birth $\dagger$ & $13(48.2)$ & $5(26.3)$ & $\begin{array}{l}1.02(0.42 \text { to } 2.52) \\
p=0.96\end{array}$ & $\begin{array}{l}0.96(0.21 \text { to } 4.27) \\
p=0.95\end{array}$ \\
\hline Health visitor discusses between 4-6 months $\dagger$ & $14(51.9)$ & $4(21.1)$ & $\begin{array}{l}1.25(0.54 \text { to } 2.91) \\
p=0.60\end{array}$ & $\begin{array}{l}1.40(0.51 \text { to } 3.85) \\
p=0.52\end{array}$ \\
\hline Health visitor discusses between 6-9 months $†$ & $26(92.8)$ & $16(84.2)$ & $\begin{array}{l}1.61(0.15 \text { to } 16.95) \\
p=0.69\end{array}$ & $\begin{array}{l}1.47(0.14 \text { to } 15.60) \\
p=0.75\end{array}$ \\
\hline
\end{tabular}

*Dichotomised as always, often or sometimes $v$ never.

†Dichotomised as always or often $v$ sometimes or never. 


\section{Key points}

- Trained midwives and health visitors had greater knowledge of the risks associated with baby walker use than untrained midwives and health visitors.

- Trained health visitors held more negative attitudes towards baby walkers and more positive attitudes towards baby walker health education than untrained health visitors.

- Trained midwives provided advice about baby walkers in the antenatal period more often than untrained midwives.

- The impact of training on parental safety behaviour, the adoption of safety practices and injury reduction requires further evaluation.

over-report walker health education than those in the control arm, this cannot explain the differences we found in knowledge between the treatment arms. The health professionals participating in this trial are likely to have been more interested in injury prevention than those not participating in the trial. It is therefore possible that our results may overestimate the effect of training in the general population of health professionals. Finally we measured our outcomes at six months after training, hence we do not know if the positive effects we found will persist in the longer term.

\section{Comparing our findings with previous research}

Our findings add support to those from studies evaluating injury prevention training that suggest training health professionals changes knowledge and attitudes and can increase the provision of injury prevention advice to parents, ${ }^{36}$ at least in the short term.

\section{Implications for injury prevention practice and research}

Despite the growing body of evidence suggesting that injury prevention training can have positive effects on the provision of injury prevention counselling and calls for more training for health professionals, ${ }^{73-16}$ there is a lack of evidence that trained health professionals can change behaviour, influence the adoption of safety practices, or reduce injury. Larger randomised trials are required for this and to examine the longer term effects of training on the knowledge, attitudes, and practices of health professionals. Preferably these trials should include validated measures of injury prevention practice such as observation or audiotaping ${ }^{6}$ to reduce the chance of differential over-reporting of practice by treatment arms.

Finally a lack of training is only one of the barriers for health professionals delivering injury prevention in practice. The impact of personal experience, ${ }^{15}{ }^{17}$ lack of time, ${ }^{13}{ }^{16}{ }^{18}$ lack of resources, ${ }^{15}{ }^{17} 19$ and lack of confidence ${ }^{20}$ will also need to be addressed in order that health professionals can make the best use of any training they receive.

\section{ACKNOWLEDGEMENTS}

The authors thank the midwives and health visitors who took part in the study and the Department of Health who funded Amanda Woods through the Primary Care Researcher Development Award scheme and Denise Kendrick through the Public Health Career Scientist award scheme.

\section{Authors' affiliations}

A Woods, D Kendrick, R Illingworth, Division of Primary Care, University of Nottingham

J Collier, Division of Child Health, University of Nottingham

K Watts, Division of Midwifery, University of Nottingham

M Dewey, Trent Institute for Health Services Research, University of Nottingham

\section{REFERENCES}

1 Zavoski RW, Burke GS, Lapidus GD, et al. Injury prevention training in pediatric residency programs. Arch Pediatr Adolesc Med 1996;150:1093-6.

2 Bass J, Christoffel K, Widome $M$, et al. Childhood injury prevention counselling in primary care settings. A critical review of the literature. Pediatrics 1993;92:544-50.

3 Marsh P, Kendrick D. Injury prevention training: is it effective. Health Education Research 1998;13:47-56.

4 Johnson C, Fein J, Campbell C, et al. Violence prevention in the primary care setting. Arch Pediatr Adolesc Med 1999;153:531-5.

5 Hall D, Hill P, Elliman D. The child surveillance handbook. Abingdon, Oxon: Radcliffe Medical Press, 1999.

6 Gielen A, Wilson M, McDonald E, et al. Randomized trial of enhanced anticipatory guidance for injury prevention. Arch Pediatr Adolesc Med 2001; 155:42-9.

7 Gerard JM, Klasner AE, Madhok M, et al. Poison prevention counseling: a comparison between family practitioners and pediatricians. Arch Pediatr Adolesc Med 2000; 154:65-70.

8 Accidental Injury Task Force. Preventing accidental injury-priorities for action. London: Accidental Injury Task Force, 2002.

9 Hall D, Elliman D. Health for all children. Oxford: Oxford University Press, 2003.

10 Townsend P. Deprivation. Journal of Social Policy 1987; 16:125-46

11 Home Accidents Surveillance System. Home accident surveillance system including leisure activities. 22nd Annual report. 1998 data. London: Department of Trade and Industry, 2000.

12 Woods A, Hapgood R, Bentley E, et al. Talking about baby walkers: insights about health education from the field. Health Education Journal 2003;62:41-9.

13 Miilunpalo S, Laitakari J, Vuori I. Strengths and weaknesses in health counseling in Finnish primary health care. Patient Education \& Counseling 1995;25:317-28.

14 Morgan PS, Carter YH. Are the training needs of community nurses and health vistors being met? Birmingham: Royal Society for the Prevention of Accidents, 1996.

15 Solomon B, Duggan A, Webster D, et al. Pediatric residents' attitudes and behaviours related to counselling adolescents and their parents about firearm safety. Arch Pediatr Adolesc Med 2002;156:769-75.

16 Wright M. Pediatric injury prevention. Preparing residents for patient counselling. Arch Pediatr Adolesc Med 1997;151:1039-43.

17 Woods A, Hapgood R, Collier J, et al. Midwives' knowledge of, attitudes to and practice with baby walkers. Midwifery 2003;19:63-71.

18 Yassi A, Cooper JE, Tate RB, et al. A randomized controlled trial to prevent patient lift and transfer injuries of health care workers. Spine 2001;26:1739-46.

19 Price JH, Conley PM, Oden L. Training in firearm safety counseling in pediatric residency programs. Arch Pediatr Adolesc Med 1997;151:306-10.

20 Ehiri JE, Watt GCM. The role of health visitors in the prevention of home accidents involving children: time for a rethink? Health Bulletin 1995;53:20-5. 